\title{
Therapeutic Plasma Exchange: A Lifesaving Therapy in Case of ANCA-associated Vasculitis with Diffuse Alveolar Hemorrhage
}

\author{
Parmatma P Tripathi ${ }^{1} \odot$, Ratti R Sharma ${ }^{2}$, Bharath Chhabria ${ }^{3}{ }^{\circ}$, Rekha Hans ${ }^{4} \odot$, Inderpaul S Sehgal ${ }^{5} \odot$
}

Indian Journal of Critical Care Medicine (2021): 10.5005/jp-journals-10071-23889

Dear Sir,

Antineutrophil cytoplasmic antibody (ANCA)-associated vasculitis (AAV) is a multisystem disorder characterized by necrosis and inflammation of the small blood vessels, involving mostly the renal and respiratory system. ${ }^{1}$ Patients presenting with diffuse alveolar hemorrhage (DAH) have a higher risk of mortality than those without $\mathrm{DAH}^{2}$ and respond to treatment with systemic glucocorticoids and cyclophosphamide or rituximab. Occasionally, patients presenting with DAH do not respond to immunosuppressive therapy, and early therapeutic plasma exchange (TPE) in addition to immunosuppressive therapy can be lifesaving. ${ }^{3}$ According to the American Society for Apheresis 2019, ANCA-AAV with DAH comes under category I (1C). ${ }^{4}$ Herein, we report a 27-year-old male who was managed successfully with TPE. Our subjects presented to our institute with a history of fever and cough for a 2-week duration and also a history of streaky hemoptysis for 1 week. He complained of breathlessness, which progressed to modified medical research council grade IV over 5 days. Chest radiograph revealed bilateral opacities involving all the lobes as shown in Figure 1, left panel. High-resolution computed tomography of the chest and contrast-enhanced computed tomography showed multiple peribronchovascular consolidations and nodules with many showing central groundglass opacification as shown in Figure 2. There was also a fall in hemoglobin from 13-8 g/dL. Serum urea, creatinine, and urine examination were within the normal limit. Spot urine protein was $104.30 \mathrm{ng} / \mathrm{dL}$ (normal $<10 \mathrm{ng} / \mathrm{dL}$ ). Spot urine creatinine was $116.31 \mathrm{mg} / \mathrm{dL}$ (normal 100-160). Spot urine protein creatinine ratio was $896.74 \mathrm{mg} / \mathrm{dL}$ (normal 30-300), suggesting proteinuria. His serum for cytoplasmic ANCA was positive both by enzyme-linked immunosorbent assay and immunofluorescence method [PR3ANCA ELISA and indirect immunofluorescence using ethanol-fixed human neutrophils as substrate]. A diagnosis of granulomatous polyangiitis was made. He was treated with three pulses $(1 \mathrm{~g} /$ day) of intravenous methylprednisolone and rituximab $\left(500 \mathrm{mg} / \mathrm{m}^{2}\right)$. However, despite the methylprednisolone pulse, his condition worsened. He had a sudden worsening of breathlessness and his oxygen requirement increased. He was transferred to the intensive care unit and was intubated and mechanically ventilated. The endotracheal aspirate was hemorrhagic. A decision was made to perform TPE for refractory DAH. He underwent three procedures requiring an exchange of $2900 \mathrm{~mL}$ of plasma in each session using central line catheter as vascular access on Spectra Optia ${ }^{\circledR}$ (Gambro

\author{
1,2,4 Department of Transfusion Medicine, Postgraduate Institute of \\ Medical Education and Research, Chandigarh, India \\ ${ }^{3,5}$ Department of Pulmonary Medicine, Postgraduate Institute of \\ Medical Education and Research, Chandigarh, India \\ Corresponding Author: Ratti R Sharma, Department of Transfusion \\ Medicine, Postgraduate Institute of Medical Education and Research, \\ Chandigarh, India, Phone: +91-172-2756480; +91-9872812657, e-mail: \\ rrsdoc@hotmail.com \\ How to cite this article: Tripathi PP, Sharma RR, Chhabria B, Hans R, \\ Sehgal IS. Therapeutic Plasma Exchange: A Lifesaving Therapy in Case \\ of ANCA-associated Vasculitis with Diffuse Alveolar Hemorrhage. \\ Indian J Crit Care Med 2021;25(7):828-829. \\ Source of support: Nil \\ Conflict of interest: None
}

BCT spectra, Lakewood, Colorado) therapeutic apheresis machine with fresh frozen plasma as a replacement fluid. After the third cycle of plasma exchange, there were no further episodes of airway hemorrhage or bleeding. The subject was subsequently weaned from the ventilator and was extubated on the fourth day of intubation. There was a significant resolution of opacities on the chest radiograph after TPE (Fig. 1, right panel). The index case highlights the role of TPE in ANCA AAV with DAH and recommends in guidelines. ${ }^{4}$ In ANCA-AAV, TPE in addition to rituximab or cyclophosphamide and glucocorticoids is recommended in presence of acute renal failure along with DAH (both should be present). However, its effectiveness in patients with DAH alone is unclear. ${ }^{5}$ TPE removes the fractionation of antibodies (ANCA) from the circulation with each session. Immunomodulation, immunoregulation, and removal of inflammatory mediators are the adjuvant benefits of TPE. ${ }^{6}$ Challenges with TPE are more in these cases when used in combination with adjuvant therapy like methylprednisolone and rituximab. There are concerns that both methylprednisolone and rituximab may be removed with sessions of TPE, although data are limited. In conclusion, TPE therapy can be considered for patients with DAH secondary to AAV.

\section{Statement of Ethics}

We are thankful to the patient, who gave informed consent for publishing this case report. This study was approved by the Institutional Review Board. 

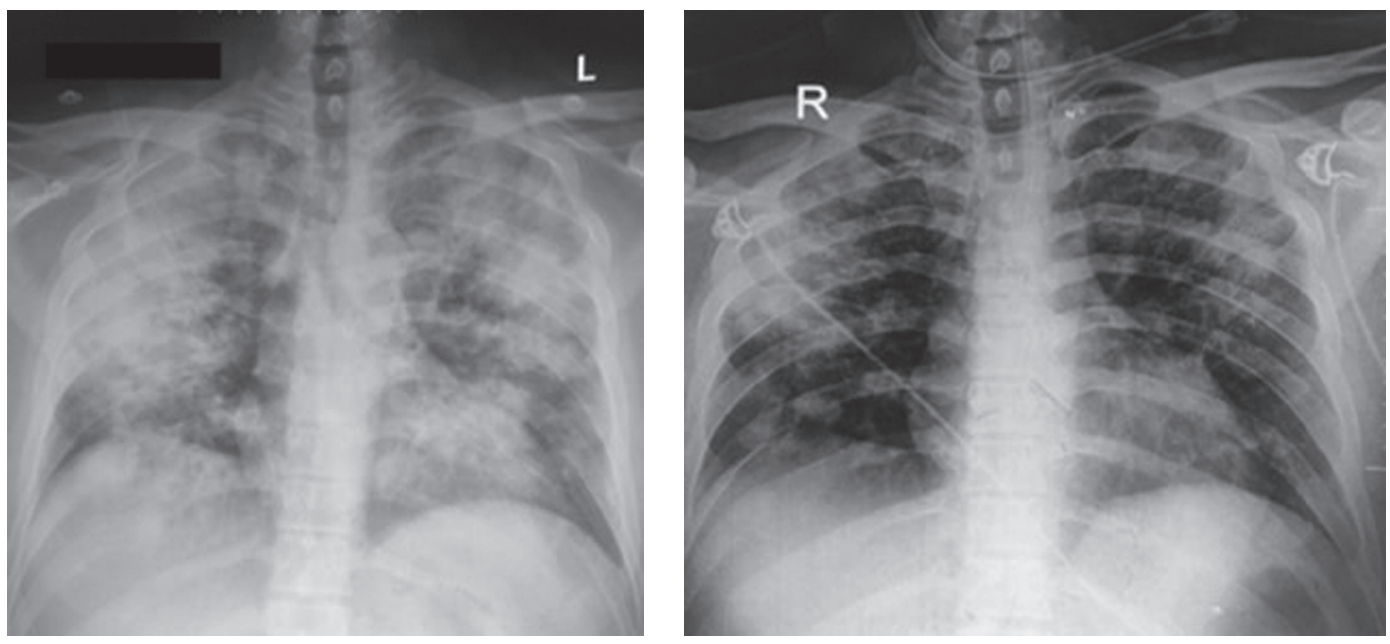

Fig. 1: Radiological comparison between pre- and post-therapeutic plasma exchange procedures (chest X-ray images)

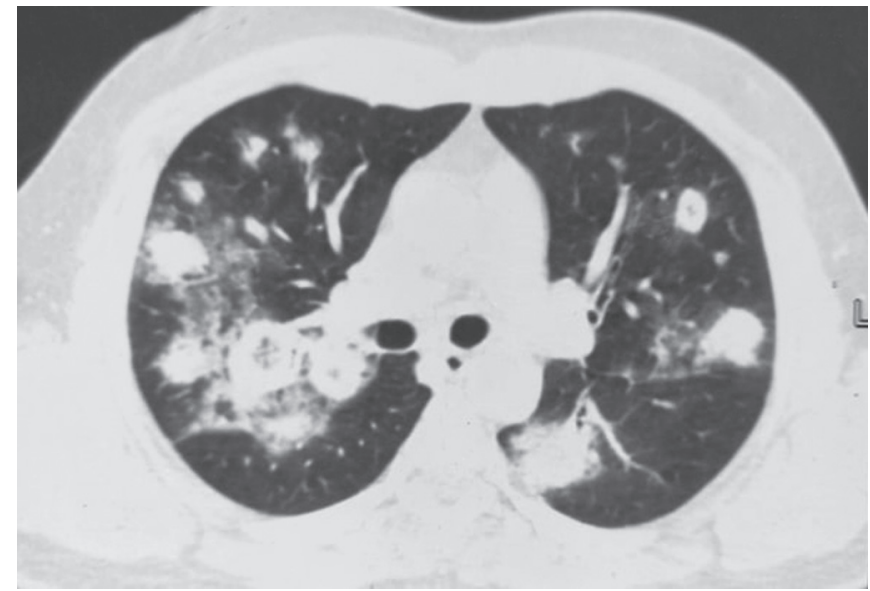

Fig. 2: High-resolution computed tomography of the thorax demonstrating multiple random nodules of varying size with some of them forming cavities

\section{Authors Contribution}

Parmatma P Tripathi and Bharath Chhabria were involved in patient management and initial drafting of the manuscript.

Rekha Hans was involved in patient management and review of the manuscript.

Inderpaul S Sehgal was involved in patient management and the final review of the manuscript.

Ratti R Sharma was involved in patient management, final drafting, and final preparation of the manuscript.

\section{OrCID}

Parmatma P Tripathi @ https://orcid.org/0000-0003-0913-8375

Ratti R Sharma (1) https://orcid.org/0000-0002-7415-4665

Bharath Chhabria (1) https://orcid.org/0000-0002-1002-3690

Rekha Hans (1) https://orcid.org/0000-0001-7101-0853

Inderpaul S Sehgal 은 https://orcid.org/0000-0002-6505-6019

\section{References}

1. Kallenberg CG. Key advances in the clinical approach to ANCAassociated vasculitis. Nat Rev Rheumatol 2014;10(8):484-493. DOI: 10.1038/nrrheum.2014.104.

2. Hogan SL, Nachman PH, Wilkman AS, Jennette JC, Falk RJ. Prognostic markers in patients with antineutrophil cytoplasmic autoantibodyassociated microscopic polyangiitis and glomerulonephritis.J Am Soc Nephrol 1996;7(1):23-32. DOI: 10.1681/ASN.V7123.

3. Levy JB, Turner AN, Rees AJ, Pusey CD. Long-term outcome of anti-glomerular basement membrane antibody disease treated withplasma exchange and immunosuppression. Ann Intern Med 2001;134(11):1033-1042. DOI: 10.7326/0003-4819-134-11-20010605000009.

4. Padmanabhan A, Smith LC, Aqui N, Balogun RA, Klingel R, Meyer E, et al. Guidelines on the use of therapeutic apheresis in clinical practice-evidence-based approach from the writing committee of the American society for apheresis: the eighth special issue. J Clin Apher 2019;34(3):171-354. DOI: 10.1002/jca.21705.

5. Alba MA, Flores-Suárez LF. Seven clinical conundrums in the treatment of ANCA-associated vasculitis. Clin Exp Rheumatol. 2013 Jan-Feb;31(1 Suppl 75):S74-83. Epub 2013 Apr 19. PMID: 23663685.

6. Walsh M, Catapano F, Szpirt W, Thorlund K, Bruchfeld A, Guillevin L, et al. Plasma exchange for renal vasculitis and idiopathic rapidly progressive glomerulonephritis: a meta-analysis. Am J Kidney Dis 2011;57(4):566-574. DOI: 10.1053/j.ajkd.2010.10.049. 